\title{
Estabelecimento do vínculo e comportamento compassivo na relação paciente/família/equipe multiprofissional, um manejo para minimizar os impactos no processo de terminalidade
}

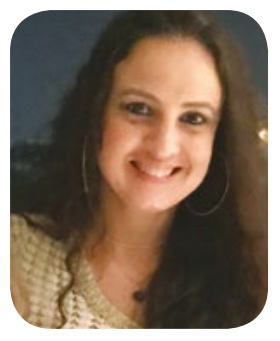

\author{
Aline Camera Cintra ${ }^{1}$
}

Palavras-chave: cuidados paliativos, comportamento compassivo, terminalidade Key words: palliative care, compassionate behavior, termination

\section{INTRODUÇÃO}

Cuidar de pessoas é um grande desafio e para tanto se faz necessário embasamento técnico, mecanismos na atuação para estabelecer uma comunicação impecável na formação e fortalecimento do vínculo.

$\mathrm{Na}$ prática em cuidados paliativos, identifica-se que a amorosidade, uma comunicação adequada, empática e congruente andam de mãos dadas, além do desenvolvimento de habilidades como a escuta compassiva e profunda, expansão da percepção, intervenção investigativa para identificação do contexto sociofamiliar, emocional, espiritual etc.

Acessar o universo de cada paciente é uma ação que requer cautela e acima de tudo respeito. Afinal é neste instante que nos deparamos com a sua essência, aquilo que é o sentido da sua vida. Mesmo quando nunca tenha sido tocado antes, exposto ou vivenciado, é nesse momento que, muitas vezes, tudo isso vem à tona. $E$ o que fazer quando não se tem muito "tempo"?

A velha pergunta: "Quanto tempo ainda tenho?" Automaticamente é resignificada para: "O que posso fazer no tempo que tenho?" Com o foco na dignidade de vida como direito inalienável, pautado nos princípios dos Cuidados Paliativos, além do impecável plano de cuidado e controle de sintomas, é possível viabilizar para essas pessoas oportunidade de concretização dos seus desejos ou resolução de pendências.

Para uns, dar uma volta de carro para apreciar a iluminação do Natal, ir à praia para sentir a brisa soprar, o som das ondas do mar, ou até mesmo carregar a filha no colo pela primeira vez é uma ação rotineira. Para outros, uma experiência única. É um pouco sobre isso que será descrito neste relato de caso.

\section{RELATO DE CASO}

Este relato de caso abordará atuação do Assistente Social junto à equipe de cuidados paliativos ao paciente I.S.A, de 40 anos, sexo masculino, soteropolitano, casado, pai de cinco filhos. Destes, dois jovens adultos (21 e 22 anos) e três menores ( 7,12 anos e uma bebê de 1 mês). Tem o seu filho primogênito (22 anos) como o seu principal cuidador no domicílio. O paciente é o único contribuinte da renda familiar. Em auxílio-doença, trabalhava como encarregado de equipe no ramo da construção civil. Residente e domiciliado na cidade de Salvador, em imóvel próprio do tipo casa, com infraestrutura adequada para as demandas da família.

Regulado de um Hospital Geral do Estado e admitido na enfermaria de Cuidados Paliativos em abril do ano vigente, com diagnóstico de neoplasia de esôfago avançada, com metástase óssea para coluna dorsal. Paciente teve o diagnóstico em setembro de 2016, submetido à realização da gastrostomia por ser considerável inoperável. Evoluiu com dor intensa e progressiva. Em janeiro do ano seguinte evoluiu com perda súbita de força muscular em membros inferiores, desde então passou a não mais deambular. Em março foi internado no Hospital Geral por quadro importante de dor, quando foi transferido para dar seguimento com a Equipe de Cuidados Paliativos deste hospital.

Lúcido, orientado, no primeiro momento, pouco comunicativo, humor tendendo à introspecção, queixando-se sempre de dor, dispneia, perda da força muscular, dificuldade de falar. Com alto nível de ansiedade e irritabilidade, ao ser abordado, relata brevemente sobre seu adoecimento, sobre suas 
perdas secundárias e os impactos físicos e psicossociais. Família com limitação de revezamento entre os acompanhantes, pois genitora em pré-operatório para cirurgia de catarata, genitor hospitalizado por fratura em membro inferior e esposa em resguardo do parto, além de cuidar dos outros filhos. Genitora e filha com relato de exaustão e dificuldade de enfrentamento, pois paciente apresenta períodos de agressividade, com ofensas verbais, gritos e exigências (por exemplo: que permaneçam sempre em pé, ao seu lado do leito). De forma contraditória, não permitia que os acompanhantes realizassem as refeições ao seu lado, pelo fato de não poder comer também. Para tanto foi realizada reunião familiar para organização de uma escala de acompanhante, bem como esclarecimento do plano de cuidado do paciente.

Paciente portador de doença oncológica avançada, irreversível, fora de possibilidade de tratamento para controle de doença. Definido com paciente e família por seguimento em Cuidados Paliativos plenos e compreendido como desproporcional medidas invasivas de suporte à vida, como internação em UTI, intubação orotraqueal, ventilação mecânica, uso de drogas vasoativas, diálise e manobras cardiorrespiratória. Veio transferido com uso de analgesia fraca. Diante do elevado quadro álgico, foi otimizado analgesia com êxito no controle da dor.

Em um segundo momento, paciente demonstra entendimento da sua condição clínica, ao tempo que questiona sobre a sua perda de performance e a possibilidade de voltar ao trabalho. Justifica seu comportamento, que hora demonstra-se arredio, irritado, entristecido e intolerante ao fato de estar distante dos filhos, em especial da filha menor, de um mês, que só a viu uma única vez e não teve a oportunidade de carregar. Durante atendimento referiu avaliar a possibilidade de receber a visita das crianças.

Após o manejo para controle de sintomas, paciente mais acessível questiona para sua médica paliativista sobre condição clínica. Refere que nenhum médico havia "parado" para conversar com ele antes. De maneira lenta e gradual foi explicado que a doença apresentou progressão para coluna, razão pela qual não conseguia mexer as pernas. Ele questionou se voltaria a andar, se ficaria bom, se ficaria sem doença, com vida normal. Foi esclarecido pela paliativista que o envolvimento da coluna significaria metástase, tornando a doença incurável. Paciente referiu entendimento que a sua condição era muito difícil e solicitou apoio para convocar a família para conversar. Falou que está sendo muito difícil lidar com a perspectiva de piora progressiva, que não gostaria de depender de terceiros, mas deseja ser mantido informado sobre tudo, para que possa planejar e definir o que fazer. Pautado no princípio da autonomia e na dignidade humana, o desejo do paciente foi cumprido e toda conduta foi compartilhada com ele e seus familiares.

Após abordagem ao paciente, contextualizando a sua real condição clínica, este passou um período bem introspectivo, com relato de "dor na alma", compreendido como dor total, aquela introduzida por Cicely Saunders, a precursora dos Cuidados Paliativos modernos, onde enfatiza a importância de se interpretar o fenômeno doloroso não somente na sua dimensão física, mas também nas suas dimensões emocionais, sociais e espirituais, que influenciam na origem e na expressão da queixa dolorosa.

O contato com a sua finitude exacerbou vários temores, mas a principal angústia era ficar sem ver seus filhos e deixá-los desamparados. Durante atendimento e diante do desejo antes exposto, de poder receber a visita dos filhos, após reunião a equipe multiprofissional, composta por médico, assistente social, enfermeira e psicóloga definiu-se por viabilizar um espaço para a efetivação deste reencontro.

Em data e hora previamente definidas, foi organizado um ambiente fora da enfermaria, com privacidade e aconchego para o paciente receber a visita da esposa, três filhos menores e a mais velha, a sua principal acompanhante hospitalar. Momento foi movido de muita emoção, pois o paciente teve a oportunidade de carregar no colo a sua filha de um mês de vida, pela primeira vez, e conversar com seus filhos maiores. Houve registro fotográfico e filmagem para eternizar esta lembrança e a equipe multiprofissional monitorou esse encontro, que aconteceu com muita tranquilidade e sem intercorrência. Após esse momento, o paciente retornou para a unidade sorrindo, dor grau zero. Noite tranquila, sem sinais de desconforto e sem despertar em nenhum momento.

No dia seguinte à visita dos familiares, o paciente abriu quadro de delirium, sendo iniciada a sedação paliativa. Familiares fragilizados, porém demonstraram entendimento do processo de finitude e associaram a piora à "missão cumprida" do paciente, em ter se despedido dos seus filhos e esposa. Quatro dias depois, o senhor I.S.A evoluiu a óbito. Familiares presentes, mobilizados, mas organizados. Diante da elegibilidade e oportunidade de ser um doador de córneas, família foi informada e de prontidão concordaram com o ato de amor ao próximo. 
Entendendo que a intervenção da equipe de saúde responsável pelos cuidados não se encerra com o evento da morte, mas pautado na filosofia dos Cuidados Paliativos, em dar continuidade durante o processo de luto. Sete dias após o falecimento do paciente foi realizado telefonema de condolências, aproveitando para oferecer um momento de acolhimento, o que favoreceu como fechamento de um ciclo de cuidado.

\section{DISCUSSÃO}

Os princípios dos Cuidados Paliativos conclamam à vida, promovendo uma assistência global focando nas diversas dimensões do indivíduo. Reconhecendo que o morrer é um processo natural, sua prática proporciona focar no que remete ao sentido da vida do paciente, não priva-o de viver e planejar sua morte de maneira digna. Desta forma, o estabelecimento de vínculo, a prática de uma escuta compassiva e profunda são ações essenciais para reduzir os impactos oriundos do processo de finitude, além de oportunizar ao paciente e sua família um espaço para resolução de pendências, construção de uma relação afetiva e verdadeira, estando atento para as suas necessidades e preferências, minimizando o seu sofrimento físico, psicossocial e espiritual.

\section{REFERÊNCIAS}

1- CARVALHO R. C. T., PARSONS, h.a. (orgs). Manual de Cuidados Paliativos ANCP, $2^{a}$ ed, Porto Alegre: sulina, 2012.

2- MARTINELLI, Maria Lúcia. et al. (orgs.). O uno e o múltiplo nas relações entre as áreas do saber. São Paulo: Cortez/ EDUC, 1995.

3- KOVACS, M. J. Educação para a morte: temas e reflexões. São Paulo: FAPESP e Casa do Psicólogo, 2003.

4- VASCONCELOS, A.M. A prática do Serviço Social: cotidiano, formação e alternativas na área de saúde. São Paulo: Cortez, 2008.

1- Serviço Social do HSI

E-mail para contato:

aliccintra@hotmail.com 